\title{
Nursing Students on the Border During a Pandemic
}

\author{
Clarissa Silva ${ }^{1}$, Lizette Villanueva ${ }^{1}$ \\ Correspondence: Clarissa Silva, 582 Oilfield Dr Horizon City Texas 79928, Lizette Villanueva, 7404 Cimarron Gap Dr. \\ El Paso Texas, 79911, USA.
}

Received: December 11, 2020

Accepted: January 4, 2021

Online Published: January 5, 2021

doi:10.11114/ijce.v4i1.5127

URL: https://doi.org/10.11114/ijce.v4i1.5127

\begin{abstract}
Recruitment, admission and retention of diverse nursing students are needed to ensure success, positively impact healthcare outcomes and relieve the nursing shortage. To ensure success in accelerated nursing programs, minority students need a variety of financial and academic support services. Nursing students are faced with multiple challenges, compiled with social determinants of health. Conditions arise that interfere with the person's ability to be successful beyond the personal, familial, academic, and social environments. Schools of nursing have the obligation and opportunity to provide competent nurses to care for the community. The challenge for nursing students on the border during a pandemic came in the offering of clinical encounters. Multiple opportunities were discovered and implemented for students during the pandemic including town hall meetings and "in progress" enrollment. A new approach in the delivery of course content and clinical experiences were developed. Recognizing and highlighting student needs during the current healthcare environment led to innovative ways in addressing the challenges nursing students faced during a pandemic on the border of the Southwest United States.
\end{abstract}

Keywords: COVID-19, pandemic, social determinants, clinical experiences, minority students, nursing education

\section{Introduction}

The year 2020 has been a challenge for the world, nation, and city of El Paso, Texas. El Paso is a border city along the state of Texas. The population in 2017 was approximately 840,410 and has since increased. While $79 \%$ of persons graduate from high school, only twenty four percent of persons hold a bachelor's degree or higher (U.S. Census Bureau, 2019). El Paso schools of nursing have the obligation and opportunity to provide competent nurses to care for the borderland community. There are five schools of nursing in this region, three offering a Bachelor of nursing for undergraduate students (Nursing Schools Almanac, 2019). Nursing students and nursing faculty have encountered multiple obstacles in their programs due to COVID-19.

COVID-19 is a predator that has been relentless in a multitude of lives in its alterations and consumption. According to the Centers for Disease Control (CDC) (2020) and World Health Organization (WHO) (2020), COVID-19 has spread in the millions globally and nationally. Locally, COVID-19 has spread into the thousands for the border of El Paso, Texas (CDC, 2020).

On March 24, 2020, nursing faculty were asked to prepare the transition of face-to-face nursing course education for an online environment. Considering a large majority of the El Paso, Texas population is minority, social determinants of health played a role in our nursing student ability to remain successful in the online environment.

Health care needs for many are unreachable if the population has social determinants of health preventing them from comprehending the available resources because of diverse backgrounds. Social determinants of health include factors in which persons are born, grow, live, work and age, these factors could affect health. Many persons are challenged in changing the social determinants of health that guide their destiny. A predisposition in an unhealthy environment can lead to exposure to toxins, poor habits, and conditions which can lead to disease and disease processes. Because minorities can have a predisposition to poverty, lack of education, and poor working conditions, these factors can affect access to and quality of care received (Thornton, \& Persaud, 2018).

Social determinants of health are the conditions that interfere with the person's ability to be successful beyond the personal, familial, academic, and social environments. Minority students are at risk. Historically as economic opportunities have hindered many from the advantages known to other societal races, minorities of any geographic region face obstacles when attempting to obtain a higher education. Some persons do not have the academic preparation 
beyond elementary school (Metcalfe \& Neubrander, 2016).

Increased resources are necessary for educational attainment. Nursing will greatly impact healthcare outcomes through the diversification of healthcare. Recruitment, retention, and support of nursing students who mirror the changing demographics of the nation will be needed to care for future patients. Minority nursing student recruitment is a necessary step in addressing the nursing shortage (American Association of Colleges of Nursing, 2019).

Snavely (2016) suggests the nursing shortage will impact not only El Paso, Texas, but the entire United States affecting the quality-of-care diverse populations receive. Since nurses are retiring and the population is aging at an alarming rate, the supply and demand are at odds. Nurses at the bedside are critical in preventing nosocomial infections which can lead to increased lengths of stay for patients. Shortages among faculty in schools of nursing create a spiraling effect in admission rates and student preparation for a nursing career.

Admission to schools of nursing is not about ethnicity, but about the ability to develop well prepared practitioners. Schools that graduate minorities enhance patient environments and outcomes of diverse populations. To make the nursing workforce applicable to populations being served, standard eight was put forth by the American Nurses Association (ANA). Admission of diverse populations of nursing students is needed to impact healthcare outcomes. Nurses are expected to become culturally competent role models and cognizant consumers of care (Glazer, et al., 2015, p. 2; Institute of Medicine, 2010; Marion, et al., 2016).

The Robert Wood foundation and the American Association of Colleges of Nursing started a campaign to relieve the nursing shortage in 2008, thus creating a new career opportunity (Millett \& Kevelson, 2015, p. 1). Minorities and many others were beneficiaries of this program. The inclusion of students with minority or low economic status in nursing schools was needed and multiple support services were offered to assist students attending accelerated nursing tracks (Millett \& Kevelson, 2015).

\subsection{Literature Review}

A synthesis of the literature was conducted to determine the available information on the topic. Several search engines were used to determine the available information on the topic including CINAHL Complete, ERIC, PubMed, Ovid, Nursing Reference Center Plus, Ojin.nursingworld.org, Census.gov, CDC, and the WHO.

Sutherland et al. (2007) made efforts in recruitment and retention to ensure success of minority populations. Test anxiety and study skills were barriers to success along with mentoring opportunities, so mentorship, tutoring, and professional development were offered at the recommendation of ethnic community leaders to ensure student success. There were efforts to improve memory with educational support with the use of the internet and web programs. Recommendations for faculty sensitivity training were necessary for teaching minority students. The study found financial resources and problem-solving approaches as barriers for student success. Student needs were inclusive of socialization and mentoring within other social groups in the academic community.

Tinto (1975) proposed that students stay or leave higher education for different reasons. His model proposes students acclimate to college either socially and/or academically. When both commitments are accomplished, the student was more likely to remain in their prospective program of study. The student who committed to the academic component was able to graduate. However, the students who committed to the social component may not graduate since there were academic commitments that had be maintained to remain in a college program. Research showed students who were committed to the college program socially remained until they were invited to leave academically due to failure.

Ferrell, et al. (2016) posit the reasons minority students leave nursing school needed further research so preventive measures could be implemented. Minorities make up only $16.8 \%$ of the Registered Nurse (RN) population within the United States (2008), this underrepresentation of the workforce would not prepare the healthcare community by 2030 (Ferrell \& Decrane, 2016; Snavely, 2016).

The reasons minorities leave undergraduate programs have been studied in one accelerated program, however the study included only two undergraduate programs, one being a state community college and the other a baccalaureate program. Findings in the study concluded minority students who entered nursing school for multiple personal reasons. To ensure minority success in the program, the students were given tutoring sessions. It was found that many of the minority students required financial assistance in terms of grants, loans, and scholarships in addition to tutoring sessions. Many minority students continued to work despite their involvement in an accelerated nursing degree program. Limitations in the study included a minimal population which did not allow for multi-variate analysis of the variables (Ferrell, et al., 2016).

In a study geared toward understanding minority retention and graduation, faculty were surveyed in 16 southeastern states including the District of Columbia. Faculty with at least five years' experience in Bachelor of Nursing (BSN) and Associates Degree in Nursing (ADN) programs were asked to participate in the study. The strategies used to assist 
minority students in their prospective nursing programs were of primary interest which included timely feedback on exams, instructor availability, and feedback on clinical performance. A limitation of the study was that only 14.5 percent of the student body were minority (Baker, 2010, p. 218).

Betts et al. (2017) identified both academic and social risk factors that indicate the reasons why undergraduate students end nursing programs in attrition. The risk factors studied pertained to burn-out, relationship to faculty, lack of preparedness for clinical, poor images of nursing, time constraints, conflicts in the demands, and differences in nursing perceptions with actual experience as a student. Creating an increased burden were the issues of finance, medical and health related issues, poor familial support, lack of social integration, and the realism of the nursing profession. Limitations in the study were the use of a perfect model for remediation and coaching. Pre-screening of students were considered helpful, but not predictive of attrition.

Populations are at risk for social determinants of health when they are closely interwoven within their own communities and the only goal is survival. Knowledge deficits related to health literacy will prevent willingness to access health services if trust of the healthcare community is not locally grown. Neubrander \& Metcalfe (2016) studied bringing healthcare to a diverse population in the Appalachian region. This was an opportunity for rural and ethnic students who were interested in nursing, however lacked the financial resources to go beyond their community for education. The experience also enabled instructors to teach in a unique environment. Community mentors tutored the participants in preparation for college entrance exams. Funding was provided for tuition and living expenses to promote success in nursing school. The limitations were project related. The project was not considered researchable, thus creating a limit on the traditional approaches of information acquisition.

Johnson (2019) proposed student classroom success was based on acquisition of basic needs. Academia which focused on technology alone would not meet the needs of today's students. While academic information on technology was not the topic, the authors linked the focus to a 2017 study conducted in Wisconsin which found "homelessness" interferes with student success (Johnson, 2019, p. 2). The conference concluded there was no federal data to support these issues.

Limitations of the literature review are that no studies have been conducted in social determinants of health as it relates to COVID-19. The contents of the literature review primarily focused on social determinants of health and academic success.

\section{Pandemic Experience}

The school of nursing has offered minority students the opportunity to become educated within an accelerated degree program. The year of 2020 set into motion an experience that would compare to no other when attempting to provide the same experience prior to the pandemic.

The challenge of nursing students on the border during a pandemic came in offering a clinical experience. As faculty, the ethical options and the best approach for the health and welfare of our students was discussed. The traditional opportunity to offer a clinical experience to our students was decided.

\subsection{Methods}

Masks were provided by the school to the faculty and students going to the clinical environment. Several town hall meetings were conducted between the students and administration. Students were given opportunities to ask questions during the town hall meetings. Students were also given the option to take a "in progress" for the clinical course enrolled if they voiced concerns about how COVID-19 could affect them or their families.

An opportunity to discover new approaches to the delivery of nursing courses was presented. Face to face teaching became an online experience throughout the remainder of the Spring and Summer of 2020. The most innovative experience was offering simulation experiences in an online format. Online simulation was carefully coordinated with the help of simulation staff and faculty. The experience, while not the same, was the best option in the current circumstances.

Challenges to the online format of teaching were encountered. Learning was stressful because students and some of the faculty were at home with their children or extended families. Nursing administration listened to feedback from students stating the face-to-face method of instruction was missed. Some issues included attending online classes, studying, and learning at home amidst distractions. A measure to improve the situation was offered by providing study rooms by appointment at the school of nursing with special attention to masking and social distancing. Tutoring sessions became necessary and opportunities to reduce course load was undertaken by some students. The Summer session produced its own challenges with time constraints and an unforgiving increase in COVID-19 in the El Paso community.

As the Fall of 2020 academic session approached, the COVID-19 exposures in the community increased with the need for curfews and strict social precautions. Student participation in clinical experiences became more crucial. Hospital 
community leaders of El Paso were in dire need of help as staff were becoming exhausted. The students were given options to attend clinical environments that were COVID-19 units. The resilience of our students proved to be beneficial to the community. New personal protective equipment was distributed to students and they were retrained on COVID-19 protective measures.

\section{Result}

The nursing faculty were successful in helping the students achieve required clinical hours to meet course requirements without any student infections. The 2020 Academic session had come to an end, and our students had given the most selfless contribution to society. Clinical experiences concluded without exposures to COVID-19 in the clinical setting.

\section{Discussion}

COVID-19 has made academic approaches to teaching challenging. In El Paso, Texas, our school of nursing used the social determinants of health and the interests of our student population to provide the best experience possible. Learning in an online environment can be challenging. We found the need to provide support to those who are visual learners. Clinical experiences were met without exposures. Nursing students on the border during a pandemic triumphed beyond the situation to achieve their goals. Our students are better prepared to handle the nursing career they chose. Many students have entered the healthcare environment knowing the times healthcare is experiencing today. While fear of the unknown can be a barrier, our students are prepared for the challenges that await them. We learned new approaches to teaching in a $100 \%$ online format and learned innovative ways to prepare tomorrow's nurses for a clinical experience despite COVID-19. Our students captured a clinical training unlike no other during a pandemic, inclusive of caring for the critically ill. Students cared for those who recovered and died. Many have been enlightened about what it takes to be in nursing.

Throughout the year of 2020, we have not seen a mass exudes of student enrollment in our nursing program, to the contrary, Spring enrollment is as high as any other year or semester. While the local and national media have focused on current registered nurses in the community and nation, we focused our attention on our nursing students who are today's hero's and tomorrows lifeline to shortage of nurses in our community.

Funding source: Not applicable

Ethical approval: Not applicable

Declaration of competing interest: None declared

\section{References}

American Association of Colleges of Nursing. (2019, April 1). Enhancing diversity in the workplace. https://www.aacnnursing.org/news-information/fact-sheets/enhancing-diversity

Baker, B. H. (2010). Faculty ratings of retention strategies for minority nursing students. Nursing Education Perspectives, 31(4), 216-220. https://pubmed.ncbi.nlm.nih.gov/20882860/

Betts, K. J., Shirley, J. A., \& Kennedy, R. (2017). Identifying academic \& social risk factors of Baccalaureate nursing students using the college persistence questionnaire. Journal of Education and Practice, 8(12), 159-167. https://eric.ed.gov/?id=EJ1140641

Centers for disease control. (2020). Cases, data, and surveillance: United States COVID-19 cases and deaths by state. https://covid.cdc.gov/covid-data-tracker/\#cases_casesinlast7days

Ferrell, D. K., \& Decrane, S. K. (2016). S.O.S. (Students' Optimal Success): A model for institutional action to support minority nursing students. Journal of Cultural Diversity, 23(2), 39-45. https://pubmed.ncbi.nlm.nih.gov/27439228/

Ferrell, D. K., Decrane, S. K., Edwards, N. E., Foli, K. J., \& Tennant, K. F. (2016). Minority undergraduate nursing student success. Journal of Cultural Diversity, 23(1), 3-11. https://pubmed.ncbi.nlm.nih.gov/27188015/

Glazer, G. Clark, A., \& Bankston, K. (2015). Legislative: From policy to practice: A case for Holistic review diversifying the nursing workforce. The Online Journal of Issues in Nursing, 20, 1-4. https://doi.org/10.3912/OJIN.Vol20No03LegCol01

Institute of Medicine. (2010). The future of nursing: Leading change, advancing health. http://www.ion.edu/ /media/Files/Report\%20Files/2010/The-Future-of-Nursing/Future\%20of\%20Nursing\%20201 0\%20Report\%Brief.pdf2010.

Johnson, S. (2019, February). Food, housing, and childcare: Colleges addressing basic needs are boosting success. In S. G. Professor, DREAM conference, Conference conducted by nonprofit Achieving the dream.

https://www.edsurge.com/news/2019-0221-food-housing-and-childcare-colleges-addressing-basic-needs-are-boosti 
ng-success

Marion, L., Douglas, M., Lavin, M. A., Barr, N., Gazaway, S., Thomas, E., \& Bickford, C. (2016). Implementing the New ANA standard 8: Culturally Congruent Practice. The Online Journal of Issues in Nursing, 22(1). https://doi.org/10.3912/OJIN.Vol22No01PPT20

Metcalfe, S. E., \& Neubrander, J. (2016). Social determinants and educational barriers to successful admission to nursing programs for minority and rural students. Journal of Professional Nursing, 32(5). 377-382. https://doi.org/10.1016/j.profnurs.2016.01.010

Millett, C. M., \&., \& Kevelson, M. J. C. (2015). A study of the influence of the new careers in nursing program on the culture of participating schools of nursing. New careers in nursing. Research report. ETS RR-15-28. ETS Research Report Series no. RR-15-30, (2330-8516), 1-41. https://doi.org/10.1002/ets2.12077

Neubrander, J., \& Metcalfe, S. E. (2016). Increasing diversity in our schools of nursing. Journal Cultural Diversity, 23(2), 46-49. https://www.ncbi.nlm.nih.gov/pubmed/27439229

Nursing Schools Almanac. (2019). List of schools in El Paso, Texas. https://www.nursingschoolsalmanac.com/articles/list-accredited-nursing-schools-el-pasotexas

Snavely, T. M. (2016). A brief economic analysis of the looming nursing shortage in the united states. Nursing Economic\$, 34(2), 98-100.

http://web.b.ebscohost.com.libraryaccess.elpaso.ttuhsc.edu/nup/pdfviewer/pdfviewer?vi=3\&sid=a215b07e-59ad-4 08f-b0ef-0608c6cf5e01\%40sessionmgr104

Sutherland, J. A., Hamilton, M. J., \& Goodman, N. (2007). Affirming at-risk minorities for success (ARMS): Retention, graduation, and success on the NCLEX-RN. Journal of Nursing, 46(8), 347-353. https://doi.org/10.3928/01484834-20070801-03

Thornton, M., \& Persaud, S. (2018). Preparing today's nurses: Social determinants of health and nursing education. The Online Journal of Issues in Nursing, 23(3). https://doi.org/10.3912/OJIN.Vol23No03Man05

Tinto, V. (1975). Dropout form higher education: A theoretical synthesis of recent research. Review of Educational Research, 45(1), 89-125. https://doi.org/10.3102/00346543045001089

United States Census Bureau. (2019). El Paso County, Texas 2017 Population Estimates. https://www.census.gov/searchresults.html?q=Population + for + El + Paso + Texas $+2019 \&$ page $=1 \&$ stateGeo=none \&se archtype $=$ web\&cssp $=$ SERP\&_charset_=UTF-8

World health organization. (2020). Coronavirus disease (COVID-19) dashboard. https://covid19.who.int/

\section{Copyrights}

Copyright for this article is retained by the author(s), with first publication rights granted to the journal.

This is an open-access article distributed under the terms and conditions of the Creative Commons Attribution license which permits unrestricted use, distribution, and reproduction in any medium, provided the original work is properly cited. 